\title{
Analisis Pengendalian Persediaan Bahan Baku Melalui Penerapan Economic Order Quantity (EOQ) pada PT Andini Megah Sejahtera Cabang Bogor
}

\author{
1) Erma Apriyanti - Dosen STIE Pandu Madania \\ 2) Lia Lestari - Alumni STIE Pandu Madania
}

\begin{abstract}
Abstrak
Penelitian ini bertujuan untuk: 1) mengetahui pengendalian persediaan di PT Andini Megah Sejahtera. 2) mengetahui bagaimana perhitungan persediaan dengan menggunakan metode Economic Order Quantity. 3) mengetahui perbandingan total biaya persediaan yang dikeluarkan perusahaan dengan perhitungan total biaya persediaan dengan metode EOQ. Penelitian ini menggunakan metode deskriptif kuantitatif dengan teknik pengumpulan data dilakukan melalui wawancara, observasi dan kepustakaan, hasil dari penelitian ini menunjukan bahwa pengendalian persediaan bahan baku di PT Andini Megah Sejahtera kurang efektif karena masih adanya kelebihan stock yang besar pada persediaan bahan baku dan total biaya persediaan. Adapun dengan menggunakan metode EOQ biaya tersebut lebih kecil dibandingkan dengan metode yang digunakan oleh perusahaan.
\end{abstract}

Kata Kunci : Persediaan, Bahan Baku, dan Economic Order Quantity

\begin{abstract}
Abstact
The purpose of this research are to learn about material inventory control in PT Andini Megah Sejahtera, to learn about inventory calculation metodh by using Economic Order Quantity (EOQ) metodh and to learn comparisation above total inventory cost by total calculation of EOQ. This research approaching by descriptive quantitattive and using data collection technique through interview, observation and librarian overview. The result of this research will describe that material inventory control in PT Andini Megah Sejahtera was not effetive because there is over-stock of raw material storage so that total inventory calculation were high. Therefore, by using EOQ metodh total calculation of the inventory are lower than before using EOQ metodh.
\end{abstract}

Keyword : Inventory, Raw material,and Economic Order Quantity 


\section{PENDAHULUAN}

Pada era globalisasi saat ini bisnis di Indonesia sangat berkembang pesat.Setiap perusahaan berlomba-lomba untuk menemukan sebuah solusi yang tepat agar dapat bertahan dan memenangkan persaingan di dalam dunia bisnis.Sukses tidaknya suatu perusahaan ditentukan oleh manajamen yang baik.

Namun, baik perusahaan jasa maupun perusahaan manufaktur memiliki tujuan ekonomis dan tujuan social.tujuan ekonomis berkenaan dengan upaya perusahaan untuk mempertahankan eksistensinya. Dalam hal ini perusahaan berupaya menciptakan laba, menciptakan pelanggan, dan menjalankan upayaupaya pengembangan dengan memusatkan perhatian pada kebutuhan masyarakat dalam hal produk yang diinginkan, kualitas, harga, kuantitas, waktu pelayanan, kegunaan produk, dan sebagainya.Banyak faktor yang mempengaruhi pencapaian tujuan tersebut.Salah satunya adalah faktor kelancaran produksi. Apabila proses produksi berjalan lancar, tujuan perusahaan akan tercapai.

Perusahaan manufaktur harus dapat mengendalikan persediaan bahan baku secara tepat dan efisien agar persediaan bahan baku untuk produksi cukup jumlahnya sehingga proses produksi dapat berjalan dengan lancar. Ukuran cuntuk jumlah persediaan tidak sama antara satu perusahaan dengan perusahaan lainnya tergantung dari volume produksinya, jenis perusahaan, dan proses produksinya.

Pengendalian persediaan pada perusahaan bertujuan meminimumkan biaya dan memaksimumkan keuntungan dalam waktu tertentu. Pengendalian persediaan harus tepat dan efisien agar proses produksi berjalan lancar dan dana yang ditanam dalam persediaan bahan baku tidak berlebihan, untuk itu dalam pengendalian persediaan bahan baku perlu ditentukan beberapa hal yaitu frekuensi pembelian bahan baku dalam satu periode, waktu pembelian, jumlah bahan baku yang dibeli dalam setiap kali pembelian, jumlah minimum bahan baku yang harus ada dalam persediaan pengaman (safety stock) agar proses produksi terhindar dari kemacetan akibat ketidaktersediaan bahan baku, dan jumlah maksimum bahan baku yang harus ada dalam persediaan agar dana yang ditanam tidak berlebihan.

PT Andini Megah Sejahtera merupakan salah satu produsen konsentrat sapi perah di Boyolali, Purwakarta dan Bogor.Konsentrat adalah bahan makanan yang memiliki gizi tinggi tetapi kandungan serat kasarnya relatif rendah dan mudah dicerna.PT Andini Megah Sejahtera memiliki peningkatan kuantitas persediaan bahan baku setiap bulannya namun belum terdapat perhitungan tentang pengendalian persediaan itu sendiri seperti bagaimana mengamankan stock produksi, maupun keadaan biaya yang dikeluarkan sehingga terjadi penumpukan persediaan yang mengakibatkan kerugian karena biaya pemesanan, 
biaya penyimpanan, biaya produksi yang meningkat dan tingkat laba yang sedikit akibat kelebihan persediaan.

\section{PUSTAKA DAN KONSEPTUAL}

\section{Persediaan}

Pengertian persediaan menurut Ikatan Akuntansi Indonesia (2008) adalah barang tersedia untuk dijual, barang dalam proses atau meliputi barang yang dibeli dan disimpan oleh pengecer untuk dijual kembali. Michel Chandra Tuerah (2014) menjelaskan bahwa persediaan meliputi barang atau bahan yang diperlukan untuk proses produksi dan distribusi yang digunakan untuk proses lebih lanjut atau dijual, sedangkan persediaan menurut Assauri (2004) adalah suatu aktiva yang meliputi barang-barang milik perusahaan dengan maksud untuk dijual dalam suatu periode usaha yang normal.

\section{Persediaan Bahan Baku}

Menurut Taslim (2014) persediaan bahan baku yaitu merupakan input yang penting dari proses transformasi menjadi produk jadi. Kekurangan bahan baku yang tersedia dapat berakibat terhentinya proses produksi. Setiap perusahaan yang menyelenggarakan kegiatan produksi akan memerlukan persediaan bahan baku. Dengan tersedianya persediaan bahan baku maka diharapkan sebuah perusahaan dapat melakukan proses produksi sesuai kebutuhan atau permintaan konsumen. Selain itu, dengan adanya persediaan bahan baku yang cukup tersedia digudang juga diharapkan dapat memperlancar kegiatan produksi perusahaan dan dapat menghindari terjadinya kekurangan bahan baku. Keterlambatan jadwal pemenuhan produk yang dipesan konsumen dapat merugikan perusahaan dalam hal ini image yang kurang baik.

\section{Tujuan Persediaan Bahan Baku}

Ahyari (2003) mengemukakan beberapa hal yang menyebabkan suatu perusahaan harus menyelenggarakan persediaan bahan baku adalah :

1. Bahan yang akan digunakan untuk pelaksanaan proses produksi perusahaan tersebut tidak dapat dibeli atau didatangkan secara satu persatu dalam jumlah unit yang diperlukan.

2. Apabila perusahaan tidak mempunyai persediaan bahan baku, sedangkan bahan baku yang dipesan belum datang maka pelaksanaan proses produksi dalam perusahaan tersebut akan terganggu.

3. Untuk menghindari kekurangan bahan baku tersebut, maka suatu perusahaan dapat menyediakan bahan baku dalam jumlah yang banyak. 


\section{Pengendalian Persediaan Bahan Baku}

Istilah pengendalian merupakan penggabungan dari dua pengertian yang sangat erat hubungannya tetapi dari masing-masing pengertian tersebut dapat diartikan sendiri-sendiri yaitu perencanaan dan pengawasan. Pengawasan tanpa adanya perencanaan terlebih dahulu tidak ada artinya, demikian pula sebaliknya perencanaan tidak akan menghasilkan sesuatu tanpa adanya pengawasan.

Pengendalian adalah proses manajemen yang memastikan dirinya sendiri sejauh hal itu memungkinkan, bahwa kegiatan yang dijalankan oleh anggota dari suatu organisasi sesuai dengan rencana dan kebijaksanaannya (Taslim, 2014).

\section{Fungsi- fungsi pengendalian persediaan}

Handoko (2000), menyatakan bahwa perusahaan melakukan penyimpanan persediaan barang karena berbagai fungsi,yaitu:

1. FungsiDecoupling Fungsi penting persediaan adalah memungkinkan operasioperasi perusahaan internal dan eksternal mempunyai kebebasan (independensi). Persediaan decouples ini memungkinkan perusahaan dapat memenuhi permintaan langganan tanpa terganggusupplier

2. Fungsi Economic LotSizing, Melalui penyimpanan persediaan, perusahaan dapat memproduksi dan membeli sumber-sumber daya dalam kuantitas yang dapat mengurangi biaya-biaya per unit. Dengan persediaan lot size ini akan mempertimbangkanpenghematan biaya.

3. FungsiAntisipasi, Sering perusahaan menghadapi fluktuasi permintaan yang dapat diperkirakan dan diramalkan berdasar pengalaman atau data masa lalu. Disamping itu, perusahaan juga sering dihadapkan pada ketidakpastian jangkawaktupengirimanbarangkembalisehinggaharusdilakukanantisipasiuntukc aramenanggulanginya.

\section{Pengertian Kuantitas Pesanan Ekonomis (Economy Order Quantity)}

Herjanto Martono (2008), mengemukakan bahwa EOQ adalah jumlah kuantitas barang yang dapat diperoleh dengan biaya yang minimal, atau sering dikatakan sebagai jumlah pembelian yang optimal. Selanjutnya,menurut Assauri (2004), jumlah pemesanan yang ekonomis (economic order quantity atau economic lot size) merupakan jumlah atau besarnya pesanan yang memiliki jumlah ordering cost dan carrying cost pertahun paling minimal. Menurut Handoko (2000), metode EOQ digunakan untuk menentukan kuantitas pesanan persediaan yang meminimumkan biaya langsung penyimpanan persediaan dan biaya kebalikannya (inverse cost) pemesanan persediaan. 


$$
\mathbf{E O Q}=\sqrt{\frac{2 . S \cdot D}{\mathrm{H}}}
$$

Keretangan:

$E O Q=$ Jumlah optimal barang per pemesanan $\left(\mathrm{Q}^{*}\right)(\mathrm{Kg})$

$\mathrm{D}=$ Permintaan tahunan barang persediaan dalam unit $(\mathrm{Kg})$

$\mathrm{S} \quad=$ Biaya pemasangan atau pemesanan setiap pesanan $(\mathrm{Rp})$

$\mathrm{H} \quad$ = Biaya penahan atau penyimpanan per unit pertahun

\section{Kebijakan Economic Order Quantity}

Untuk mengoptimalkan persediaan bahan baku yang dapat menekan biaya persediaan sehingga terwujud efesiensi persediaan bahan baku, perusahaan perlu menentukan kebijakan EOQseperti :

1. Menentukan Jumlah Pembelian yang Ekonomis

2. Menentukan Persediaan Pengaman (Safety Stock)

3. Menentukan Titik Pemesanan Kembali (Reorder Point)

\section{Keterkaitan Pengendalian Persediaan Bahan Baku Menggunakan Metode Economic Order Quantity}

Baroto (2002) Kegunaan persediaan yaitu mengurangi resiko keterlambatan datangnya bahan-bahan yang dibutuhkan untuk proses produksi perusahaan, mengurangi resiko penerimaan bahan baku yang dipesan tetapi tidak sesuai dengan pesanan, mempertahankan stabilitas operasi produksi, upaya penggunaan mesin optimal.

Handoko (2000), menyatakan bahwa perusahaan melakukan penyimpanan persediaan barang karena berbagai fungsi yaitu fungsidecoupling, fungsi economic lotsizing, fungsiAntisipasi, dari fungsi-fungsi tersebut pengendalian persediaan dapat membuat perusahaan sukses dan memprediksikan cara mengantisipasi kerugian akibat persediaan.

Yamit (2008) :Metode Economic Order Quantity (EOQ) adalah jumlah kuantitas barang yang dapat diperoleh dengan biaya yang minimal atau sering dikatakan sebagai jumlah pembelian yang optimal. Dalam menentukan besarnya jumlah pembelian yang optimal ini yang perlu diperhatikan adalah biaya variabel dari penyediaan pengadaan tersebut, baik biaya variabel yang sifat perubahannya searah dengan penambahan jumlah pengadaan, maupun biaya variabel yang sifat perubahannya berlawanan dengan jumlah pengadaan tersebut. 


\section{Penelitian Terdahulu}

1. I Gusti Ayu Widi Astuti (2013), tentang "Penerapan Metode Economic Order Quantity Persediaan Bahan Baku pada Perusahaan Kopi Bubuk Bali Cap Banyuatis".

2. Chandra Herawan dkk (2013) dengan judul “Penerapan Metode Economic Order Quantity dalam Mewujudkan Efesiensi Persediaan PT Setiajaya Mobilindo Bogor “

3. Michel Chandra Tuerah (2014) dengan judul " Analisis Pengendalian Persediaan Bahan Baku Ikan Tuna pada CV. Golden KK”

\section{METODE PENELITIAN}

\section{Desain Penelitian}

Metode yang digunakan dalam penelitian ini adalah metode deskriptif kuantitatif.

\section{Operasional Variabel}

Variabel penelitian ini adalah pengendalian persediaan bahan baku. Variabel dan indikator yang digunakan dapat dilihat pada tabel berikut:

Tabel 1 Operasional Variabel

\begin{tabular}{|c|c|c|c|c|c|}
\hline Variabel & Konsep & Dimensi & Indikator & Ukuran & Skala \\
\hline $\begin{array}{l}\text { Pengendalian } \\
\text { Persediaan }\end{array}$ & $\begin{array}{l}\text { Pengendalian } \\
\text { persediaan bahan } \\
\text { baku } \\
\text { didefinisikan } \\
\text { sebagai } \\
\text { serangkaian } \\
\text { kebijakan untuk } \\
\text { menentukan } \\
\text { persediaan } \\
\text { (Herjanto, 2008) }\end{array}$ & $\begin{array}{l}\text { Total } \\
\text { Biaya } \\
\text { Persediaa } \\
\text { n }\end{array}$ & $\begin{array}{l}\text { 1. EOQ } \\
\text { 2. ROP } \\
\text { 3. SS } \\
\text { 1. } \\
\text { Ordering } \\
\text { cost } \\
2 . \\
\text { Carrying } \\
\text { cost }\end{array}$ & $\begin{array}{l}\text { 1. } \mathrm{EOQ}=\sqrt{\begin{array}{c}2 . S \cdot D \\
H\end{array}} \\
\text { 2. } \mathrm{ROP}=(\mathrm{LT} \times \mathrm{AU})+ \\
\mathrm{SS} \\
\text { 3. } \mathrm{SS}=\text { lead time } \mathrm{x} \\
\text { (Tingkat penggunaan } \\
\text { maksimal- tingkat rata2 } \\
\text { penggunaan bahan } \\
\text { baku) } \\
\text { TIC= TOC + TCC }\end{array}$ & Rasio \\
\hline
\end{tabular}

\section{Teknik pengumpulan data}

Teknik pengumpulan data yang digunakan dalam penelitian ada 3 metode yaitu :

a. Wawancara, metode ini mengajukan pertanyaan-pertanyaan secara langsung dengan responden yang diharapkan mendapat penjelasan tentang pendapat, 
sikap dan keyakinan informan tentang hal-hal yang relevan dengan fokus penelitian.

b. Observasi merupakan pengumpulan data dengan melihat langsung, mendengar dan mengamati objek yang akan diteliti dan dipergunakan untuk menyesuaikan data yang diperoleh.

c. Kepustakaan, mencari data berupa catatan-catatan, dokumen, foto-foto sebagai pelengkap data primer.

\section{HASIL DAN PEMBAHASAN}

\section{Hasil}

\section{Sistem Pengendalian Persediaan Perusahaan}

Sistem pengendalian persediaan yang saat ini digunakan perusahaan adalah sistem tradisional dimana tidak adanya perhitungan persediaan yang optimal dan ekonomis, kepala gudang hanya sekedar berasumsi bahwa jika setiap akan melakukan produksi maka harus dilakukan pembelian bahan baku serta hanya menyimpulkan bahwa yang terpenting adalah banyaknya jumlah persediaan yang tersedia di gudang tanpa melakukan perhitungan dan mementingkan biaya yang terjadi akibat menumpuknya jumlah persediaan bahan baku di gudang.

\section{Perhitungan Frekuensi Pembelian Bahan Baku dengan Metode Perusahaan dan Economic Order Quantity}

Tabel 2

Perhitungan Frekuensi Pemesanan Ekonomis Bahan Baku Tahun 2015

\begin{tabular}{|c|c|c|c|c|}
\hline No & $\begin{array}{l}\text { Jenis } \\
\text { Baku }\end{array}$ & $\begin{array}{l}\text { Kuantitas Pemesanan } \\
\text { Ekonomis } \\
\text { Perhitungan EOQ (a) }\end{array}$ & $\begin{array}{l}\text { Total } \\
\text { Pemakaian } \\
\text { Bahan Baku } \\
\text { Tahun } 2015(\text { b) } \\
\end{array}$ & $\begin{array}{l}\text { Frekuensi } \\
\text { Pemesanan } \\
\text { ekonomis } \\
(=\mathbf{b} / \mathbf{a}) \\
\end{array}$ \\
\hline 1 & Polard & $71.707 \mathrm{Kg}$ & $132.000 \mathrm{Kg}$ & 2 Kali \\
\hline 2 & Onggok & $359.031 \mathrm{Kg}$ & $1.926 .000 \mathrm{Kg}$ & 6 Kali \\
\hline 3 & Dedak & $268.903 \mathrm{Kg}$ & $990.000 \mathrm{Kg}$ & 4 Kali \\
\hline 4 & Premix & $73.925 \mathrm{Kg}$ & $60.000 \mathrm{Kg}$ & 1 Kali \\
\hline 5 & Molases & $175.220 \mathrm{Kg}$ & $536.500 \mathrm{Kg}$ & 4 Kali \\
\hline 6 & $\mathrm{~B} 122$ & $70.749 \mathrm{Kg}$ & $80.750 \mathrm{Kg}$ & 2 Kali \\
\hline 7 & Tepung Roti & $327.298 \mathrm{Kg}$ & $1.650 .000 \mathrm{Kg}$ & 6 Kali \\
\hline 8 & Bungkil Kopra & $114.387 \mathrm{Kg}$ & $330.000 \mathrm{Kg}$ & 3 Kali \\
\hline 9 & Bungkil Sawit & $243.578 \mathrm{Kg}$ & $528.000 \mathrm{Kg}$ & 3 Kali \\
\hline 10 & SG 5011 & $14.588 \mathrm{Kg}$ & $49.950 \mathrm{Kg}$ & 4 Kali \\
\hline 11 & Garam & $26.890 \mathrm{Kg}$ & $19.800 \mathrm{Kg}$ & 1 Kali \\
\hline 12 & Ampas Kedelai & $126.324 \mathrm{Kg}$ & $198.000 \mathrm{Kg}$ & 2 Kali \\
\hline 13 & Soya & $62.100 \mathrm{Kg}$ & $99.000 \mathrm{Kg}$ & 2 Kali \\
\hline Total & & $1.934 .701 \mathrm{Kg}$ & $6.600 .000 \mathrm{Kg}$ & 40 Kali \\
\hline
\end{tabular}


Perhitungan Total Pembelian Bahan Baku dengan Metode Perusahaan dan Economic Order Quantity

\section{Tabel 3}

Total Pembelian Bahan Baku Tahun 2015

(Satuan Rupiah)

\begin{tabular}{|c|c|c|c|c|}
\hline No & $\begin{array}{l}\text { Jenis } \\
\text { Baku }\end{array}$ & $\begin{array}{l}\text { Pembelian } \\
\text { Perusahaan }\end{array}$ & $\begin{array}{l}\text { Pembelian } \\
\text { Menurut EOQ }\end{array}$ & Selisih \\
\hline 1 & Januari & 1.029 .319 .956 & 743.634 .380 & 286.685 .576 \\
\hline 2 & Februari & 1.149 .522 .030 & 798.635 .200 & 350.886 .830 \\
\hline 3 & Maret & 1.149 .635 .352 & 984.292 .330 & 165.343 .022 \\
\hline 4 & April & 1.124 .974 .078 & 1.023 .036 .750 & 101.937 .328 \\
\hline 5 & Mei & 1.257 .755 .487 & 923.309 .000 & 334.446 .487 \\
\hline 6 & Juni & 1.139 .825 .900 & 898.485 .100 & 241.340 .800 \\
\hline 7 & Juli & 1.118 .671 .410 & 1.080 .649 .010 & 38.022 .400 \\
\hline 8 & Agustus & 1.850 .788 .330 & 3.410 .165 .080 & $(1.559 .376 .750)$ \\
\hline 9 & September & 1.239 .087 .660 & 869.601 .170 & 369.485 .970 \\
\hline 10 & Oktober & 1.269 .670 .660 & 855.655 .670 & 414.014 .990 \\
\hline 11 & November & 1.277 .711 .190 & 957.478 .590 & 320.232 .600 \\
\hline 12 & Desember & 1.230 .239 .420 & 1.018 .732 .720 & 211.506 .700 \\
\hline \multicolumn{2}{|c|}{ Total Pembelian } & 14.837 .200 .953 & 13.018 .732 .720 & 1.273 .525 .953 \\
\hline
\end{tabular}

Sumber : PT Andini Megah Sejahtera (2015)

\section{Perhitungan Safety Stock dengan Metode Economic Order Quantity}

\section{Tabel 4}

Persediaan Pengaman

\begin{tabular}{llllll}
\hline No & Jenis & $\begin{array}{l}\text { Lead } \\
\text { Time } \\
\text { ( Hari) }\end{array}$ & $\begin{array}{l}\text { Bahan } \\
\text { Maksimal }(\text { Kg) }\end{array}$ & $\begin{array}{l}\text { Baku } \\
\text { Bahan Baku } \\
\text { Rata-Rata } \\
\text { (Kg) }\end{array}$ & $\begin{array}{l}\text { Safety Stock } \\
(\text { Kg) }\end{array}$ \\
\hline 1 & Polard & 2 & 500 & 367 & 267 \\
2 & Onggok & 2 & 7.295 & 5.350 & 3.891 \\
3 & Kulit Kopi & 2 & 3.750 & 2.750 & 2.000 \\
4 & Premix & 2 & 227 & 167 & 121 \\
5 & Molasses & 3 & 2.032 & 1.490 & 1.626 \\
6 & B 122 & 3 & 306 & 224 & 245 \\
7 & Tepung Roti & 3 & 6.250 & 4.583 & 5.000 \\
8 & Bungkil Kopra & 2 & 1.250 & 917 & 667 \\
9 & Bungkil Sawit & 3 & 2.000 & 1.467 & 1.600 \\
10 & SG 5011 & 2 & 189 & 139 & 101 \\
11 & Garam & 3 & 75 & 55 & 60 \\
12 & Ampas Kedelai & 2 & 750 & 550 & 400 \\
13 & Soya & 1 & 375 & 275 & 100 \\
\hline Total & & $\mathbf{2 5 . 0 0 0}$ & $\mathbf{1 8 . 3 3 3}$ & $\mathbf{1 6 . 0 7 7}$ \\
\hline
\end{tabular}

Sumber : PT Andini Megah Sejahtera (2015) 
Safety Stock $=(($ Pemakaian bahan baku maksimal-pemakaian bahan baku ratarata)X waktu tunggu) maka,

$\begin{aligned} \text { Safety Stock Polard } & =\left((500 \mathrm{Kg}-367 \mathrm{Kg})^{* 2}\right) \\ & =267 \mathrm{Kg} \\ \text { Safety Stock Onggok } & =((7.295 \mathrm{Kg}-5.350 \mathrm{Kg}) * 2) \\ & =3.891 \mathrm{Kg} \\ \text { Safety Stock Kulit Kopi } & =\left((3.750 \mathrm{Kg}-2.750)^{* 2}\right) \\ \text { Safety Stock Premix } & =2.000 \mathrm{Kg} \\ & =\left((227 \mathrm{Kg}-167 \mathrm{Kg})^{*} 2\right) \\ \text { Safety Stock Molases } & =121 \mathrm{Kg} \\ \text { Safety Stock B 122 } & =((2.032 \mathrm{Kg}-1.490 \mathrm{Kg}) * 3) \\ \text { Safety Stock Tepung Roti } & =((6.250 \mathrm{Kg}-4583 \mathrm{Kg}) * 3) \\ \text { Safety Stock Bungkil Kopra } & =((1.250 \mathrm{Kg}-917 \mathrm{Kg}) * 2) \\ & =667 \mathrm{Kg} \\ & =5.000 \mathrm{Kg} \\ & \end{aligned}$

Begitupun bahan baku lainnya sehingga dari tabel 4 diketahui bahwa penggunaan bahan baku maksimal sebesar $25.000 \mathrm{~kg} / \mathrm{hari}$ didapatkan dari maksimal kapasitas kemampuan mesin produksi perusahaan dalam satu hari, sedangkan bahan baku rata-rata didapatkan dari pemakaian bahan baku tahun 2015 dan menghasilkan total persediaan pengaman bahan baku sebesar 16.077 $\mathrm{Kg}$.

\section{Perhitungan Reorder Point dengan Metode Economic Order Quantity}

$\begin{array}{ll}\text { Perhitungan ROP }=(\text { Lead Time } x \text { Average Use })+\text { SS } \\ \text { Reorder Point Polard } & =((2 * 367 \mathrm{Kg})+267 \mathrm{Kg}) \\ & =1.000 \mathrm{Kg} \\ \text { Reorder Point Onggok } & =((2 * 5.350 \mathrm{Kg})+3.891 \mathrm{Kg}) \\ & =14.591 \mathrm{Kg} \\ \text { Reorder Point Kulit Kopi } & =((2 * 2.750 \mathrm{Kg})+2.000 \mathrm{Kg}) \\ & =7.500 \mathrm{Kg} \\ \text { Reorder Point Premix } & =((2 * 167 \mathrm{Kg})+121 \mathrm{Kg}) \\ \text { Reorder Point Molasses } & =455 \mathrm{Kg} \\ & =((3 * 1.490 \mathrm{Kg})+1.626 \mathrm{Kg}) \\ \text { Reorder Point B } 122 & =6.079 \mathrm{Kg} \\ & =((3 * 224 \mathrm{Kg})+245 \mathrm{Kg}) \\ & =918 \mathrm{Kg}\end{array}$


Begitupun bahan baku lainnya sehingga dari Tabel 5 menunjukan bahwa pemesanan kembali bahan baku berbeda-beda seperti berikut.

\section{Tabel 5}

Reorder Point

\begin{tabular}{|c|c|c|c|c|c|c|}
\hline No & Jenis & $\begin{array}{l}\text { Lead Time } \\
\text { ( Hari) }\end{array}$ & $\begin{array}{l}\text { Average Use } \\
\text { (Kg) }\end{array}$ & $\begin{array}{l}\text { Safety } \\
(\mathrm{Kg})\end{array}$ & Stock & $\begin{array}{l}\text { ROP } \\
(\mathrm{Kg})\end{array}$ \\
\hline 1 & Polard & 2 & 367 & 267 & & 1.000 \\
\hline 2 & Onggok & 2 & 5.350 & 3.891 & & 14.591 \\
\hline 3 & Kulit Kopi & 2 & 2.750 & 2.000 & & 7.500 \\
\hline 4 & Premix & 2 & 167 & 121 & & 455 \\
\hline 5 & Molasses & 3 & 1.490 & 1.626 & & 6.079 \\
\hline 6 & В 122 & 3 & 224 & 245 & & 918 \\
\hline 7 & Tepung Roti & 3 & 4.583 & 5.000 & & 18.750 \\
\hline 8 & Bungkil Kopra & 2 & 917 & 667 & & 2.500 \\
\hline 9 & Bungkil Sawit & 3 & 1.467 & 1.600 & & 6.000 \\
\hline 10 & SG 5011 & 2 & 139 & 101 & & 378 \\
\hline 11 & Garam & 3 & 55 & 60 & & 225 \\
\hline 12 & Ampas Kedelai & 2 & 550 & 400 & & 1.500 \\
\hline 13 & Soya & 1 & 275 & 100 & & 378 \\
\hline \multicolumn{2}{|c|}{ Total } & & 18.333 & 16.077 & & 60.288 \\
\hline
\end{tabular}

Sumber : PT Andini Megah Sejahtera (2015)

Perhitungan Economic Order Quantity

$$
\begin{aligned}
\text { Perhitungan EOQ } & =\sqrt{\frac{2 . S . D}{H}} \\
\text { EOQ Polard PH 131 } & =\sqrt{\frac{2 * \mathrm{Rp} 800.000 * 29.000 \mathrm{Kg}}{4,04 \% * \mathrm{Rp} 3.000}} \\
& =19.568 \mathrm{~kg}
\end{aligned}
$$

$$
\begin{aligned}
\text { EOQ Polard H } 132 & =\sqrt{\frac{2 * \mathrm{Rp} 800.000 * 49.000 \mathrm{Kg}}{4,04 \% * \mathrm{Rp} 3000}} \\
& =25.436 \mathrm{Kg}
\end{aligned}
$$

$$
\begin{aligned}
\text { EOQ Polard P 132 } & =\sqrt{\frac{2 * \mathrm{Rp} 800.000 * 54.000 \mathrm{~kg}}{4,04 \% * \mathrm{Rp} 3000}} \\
& =26.703 \mathrm{Kg}
\end{aligned}
$$


Tabel 6

Hasil Perhitungan EOQ

\begin{tabular}{llllll}
\hline No & Bahan Baku & $\begin{array}{l}\text { PH 131 } \\
\text { SQRT }\end{array}$ & $\begin{array}{l}\text { H 132 } \\
\text { SQRT }\end{array}$ & $\begin{array}{l}\text { P 132 } \\
\text { SQRT }\end{array}$ & Total \\
\hline 1 & Polard & 19.568 & 25.436 & 26.703 & 71.707 \\
2 & Onggok & 99.230 & 128.986 & 130.816 & 359.031 \\
3 & Kulit Kopi & 73.382 & 95.386 & 100.135 & 268.903 \\
4 & Premix & 15.852 & 20.606 & 37.467 & 73.925 \\
5 & Molases & 48.868 & 59.668 & 66.684 & 175.220 \\
6 & B122 & 18,381 & 16.895 & 35.472 & 70.749 \\
7 & Tepung Roti & 89.317 & 116.101 & 121.880 & 327.298 \\
8 & Bungkil Kopra & 31.215 & 40.576 & 42.596 & 114.387 \\
9 & Bungkil Sawit & 66.471 & 86.403 & 90.704 & 243.578 \\
10 & SG 5011 & 2.370 & 8.983 & 3.235 & 14.588 \\
11 & Garam & 7.338 & 9.539 & 10.013 & 26.890 \\
12 & Ampas Kedelai & 34.473 & 44.810 & 47.041 & 126.324 \\
13 & Soya & 16.947 & 22.029 & 23.125 & 62.100 \\
& & & & \\
\hline Total & & $\mathbf{5 2 3 . 4 1 3}$ & $\mathbf{6 7 5 . 4 1 8}$ & $\mathbf{7 3 5 . 8 7 1}$ & $\mathbf{1 . 9 3 4 . 7 0 1}$ \\
\hline
\end{tabular}

Sumber : PT Andini Megah Sejahtera (2015)

Berdasarkan tabel 6 dapat dilihat bahwa jumlah pemesanan ekonomis setiap kali melakukan pemesanan yaitu sebesar $1.934 .701 \mathrm{Kg}$ bahan baku keseluruhan, sedangkan frekuensi pemesanan barang untuk tahun 2015 dapat diketahui dengan menghitung jumlah barang yang dibutuhkan dan hasil perhitungan EOQ.

\section{Perhitungan Total Biaya Persediaan Bahan Baku Menurut Metode Perusahaan dan EOQ}

Tabel 7 dibawah ini menunjukan total biaya pemesanan dan penyimpanan menurut perhitungan perusahaan dan perhitungan dengan metode EOQ, dapat dilihat bahwa terdapat perbedaan biaya yang dikeluarkan perusahaan jika dilihat dari tabel 7 PT Andini Megah Sejahatera dapat menurunkan biaya persediaan bahandengan selisih perhitungan perusahaan dengan metode EOQ. Sedangkan dari Tabel 8 menunjukan bahwa perhitungan biaya persediaan dengan menggunakan metode Economic Order Quantity lebih rendah dibandingkan biaya persediaan perusahaan dengan metode tradisional, karenanya menggunakan metode EOQakan meminimalkan pengeluaran biaya persediaan. Total biaya yang dikeluarkan untuk mendapatkan barang juga dapat digunakan serendah mungkin dan menghindarkan terjadinya persediaan yang menumpuk dan mengantisipasi kekurangan persediaan. 
Tabel 7

Perhitungan Total Biaya Pemesanan dan Penyimpanan

(Satuan Rupiah)

\begin{tabular}{lllll}
\hline Bahan Baku & Perusahaan & & Metode EOQ & \\
& $\begin{array}{l}\text { Biaya } \\
\text { Pemesanan }\end{array}$ & $\begin{array}{l}\text { Biaya } \\
\text { Penyimpanan }\end{array}$ & $\begin{array}{l}\text { Biaya } \\
\text { Pemesanan }\end{array}$ & $\begin{array}{l}\text { Biaya } \\
\text { Penyimpanan }\end{array}$ \\
\hline Polard & 5.600 .000 & 14.756 .439 & 1.500 .000 & 14.460 .000 \\
Onggok & 8.000 .000 & 207.960 .716 & 4.200 .000 & 210.984 .545 \\
Kulit Kopi & 6.300 .000 & 106.890 .786 & 4.000 .000 & 108.450 .000 \\
Premix & 2.800 .000 & 9.166 .534 & 1.000 .000 & 6.572 .727 \\
Molases & 3.600 .000 & 63.073 .467 & 2.400 .000 & 58.771 .136 \\
B122 & 2.400 .000 & 10.522 .239 & 1.000 .000 & 8.845 .795 \\
Tepung Roti & 8.000 .000 & 200.898 .094 & 3.500 .000 & 180.750 .000 \\
Bungkil Kopra & 4.750 .000 & 36.152 .126 & 3.600 .000 & 36.150 .000 \\
Bungkil Sawit & 3.000 .000 & 58.897 .125 & 2.700 .000 & 57.840 .000 \\
SG 5011 & 4.500 .000 & 7.045 .167 & 3.200 .000 & 5.471 .795 \\
Garam & 2.000 .000 & 5.889 .713 & 400.000 & 2.169 .000 \\
Ampas Kedelai & 3.200 .000 & 26.771 .421 & 1.500 .000 & 21.690 .000 \\
Soya & 3.200 .000 & 12.924 .171 & 1.500 .000 & 10.845 .000 \\
& & & & \\
\hline Total & $\mathbf{5 7 . 3 5 0 . 0 0 0}$ & $\mathbf{7 6 0 . 9 4 7 . 9 9 8}$ & $\mathbf{3 0 . 5 0 0 . 0 0 0}$ & $\mathbf{7 2 3 . 0 0 0 . 0 0 0}$
\end{tabular}

Sumber : PT Andini Megah Sejahtera (2015)

Tabel 8

Total Biaya Persediaan

\begin{tabular}{llllc}
\hline No & $\begin{array}{l}\text { Total Biaya Persediaan Menurut } \\
\text { Perusahaan }\end{array}$ & $\begin{array}{l}\text { Total Biaya } \\
\text { Menurut EOQ }\end{array}$ & Persediaan & Selisih \\
\hline 1 & 818.297 .998 & 749.300 .000 & 68.997 .998 \\
\hline
\end{tabular}

Sumber : PT Andini Megah Sejahtera (2015)

\section{Pembahasan}

Berdasarkan hasil penelitian pengendalian persediaan PT Andini Megah Sejahtera masih kurang optimal karena tidak adanya metode khusus dan perhitungan untuk mengendalikan jumlah persediaan maupun pembelian bahan baku dan menurut hasil perhitungan yang telah dilakukan maka diketahui bahwa terjadinya perbedaan biaya antara metode yang diterapkan perusahaan dengan motode EOQ, dapat dilihat bahwa pada Tabel 8, tabel tersebut menjelaskan perhitungan total biaya persediaan dengan metode EOQ lebih kecil dibandingkan dengan total biaya persediaan yang dikeluarkan oleh perusahaan, dan jika dilihat dari Tabel 4 frekuensi pembelian dalam satu tahun lebih sedikit, yaitu 30 kali pemesanan dalam setahun bila menggunakan metode EOQ dibandingkan dengan pemesanan perusahaan. 
Frekuensi pembelian yang sedikit akan menekan biaya pemesanan yang harus dikeluarkan oleh perusahaan. Sehingga dari pembahasan di atas penelitia ini sejalan dengan penelitian sebelumnya dari Widi (2013), Herawan (2013) dan Tuerah (2014) yaitu, berdasarkan perhitungan menggunakan metode EOQ dapat menurunkan biaya persediaan yang harus dikeluarkan oleh perusahaan, serta mampu mengetahui jumlah pemesanan ekonomis bahan baku, maupun mengetahui kapan harus dilakukan pembelian ulang bahan baku agar terjadi optimalisasi pada pengendalian bahan baku perusahaan.

\section{KESIMPULAN DAN SARAN}

\section{Kesimpulan}

Berdasarkan hasil penelitian dan pembahasan, maka dapat diambil kesimpulan yaitu:

1. Sistem pengendalian persediaan bahan baku di PT Andini Megah Sejahtera masih belum optimal karena hanya berdasarkan asumsi dari bagian gudang yang terkait dalam pemesanan ataupun pembelian bahan baku tanpa menghitung apakah persediaan di gudang masih mencukupi untuk produksi tanpa harus membeli bahan baku atau tidak, sehingga masih banyaknya persediaan yang mengganggur di gudang, sehingga meningkatkan biaya bagi perusahaan baik biaya penyimpanan maupun biaya penyusutan.

2. Perhitungan persediaan bahan baku menggunakan EOQ menunjukan bahwa pemesanan ekonomis masing-masing persediaan bahan baku berbeda-beda dengan waktu yang berbeda jika menggunakan metode EOQ perusahaan dapat melihat pemesanan yang ekonomis dalam setiap kali pemesanan sehingga akan mempengaruhi biaya pemesanan.

3. Jika dibandingkan dengan hasil perhitungan metode EOQ dari total biaya persediaan bahan baku dengan menggunakan metode EOQ lebih kecil dibandingkan dengan total biaya persediaan yang telah dikeluarkan oleh PT Andini Megah Sejahtera sehingga ada penghematan biaya persediaan bahan baku jika PT Andini Megah Sejahtera menggunakan metode EOQ dalam kebijakan pengendalian persediaan bahan bakunya.

\section{Saran}

Berdasarkan kesimpulan hasil penelitian dan pembahasan, dapat diajukan beberapa saran sebagai berikut.

1. Sebaiknya perusahaan meninjau kembali pengendalian persediaan bahan baku yang selama ini telah dilakukan. Hal tersebut, karena dari hasil penelitian ditemukan bahwa perhitungan perusahaan lebih banyak mengeluarkan biaya dibandingkan menggunakan metode EOQ. 
2. PT Andini Megah Sejahtera dapat mempertimbangkan metode EOQ untuk diterapkan pada perusahaan sehingga perusahaan dapat mengurangi biaya persediaan.

\section{DAFTAR PUSTAKA}

Ahyari. 2003. Manajemen Produksi Pengendalian Produksi II, Yoygakarta : BPFE UGM

Assauri, Sofyan. 2004. Manajemen Produksi dan Operasi. LPFE Universitas Indonesia, Jakarta.

Astuti, Widi , Wayan Cipta dan Made Ary. 2013. "Penerapan Metode Economic Order Quantity Persediaan Bahan Baku pada Perusahaan Kopi”. FEB Universitas Pendidikan Ganesha. Vol. 4 .No. 1.

Baroto. 2002. Perencanaan dan Pengendalian Produksi. PT Ghalia Indonesia. Jakarta

Carter. 2009. Manajemen Keuangan. Diunduh dari http://ekonomi.com/metodeeoq/reorderpoint/index.html Tanggal 22 Februari 2016

DT Johns dan H.A Harding. 2001. Jenis-Jenis Persediaan. Diunduh darihttp://gudangmakalah.blogspot.com/2009/02/makalah-persediaanjenis.html Tanggal 20 Februari 2016.

Fuad. 2000. Ekonomi Masyarakat. Diunduh dari $\begin{array}{ll}\text { http://koleksiilmiah.blogspot.com/tujuanekonomis.html Tanggal } & 12\end{array}$ Januari 2016.

Gitosudarmo. 2002. Anggaran Perusahaan, Yogyakarta : Badan Penerbit Fakultas Ekonomi UGM

Handoko. 2000. Dasar-dasar Manajemen Produksi dan Operasi. Yogyakarta : Badan Penerbit Fakultas Ekonomi UGM

Herawan, Chandra, Udin Pramiudi dan Edison. 2013. “Penerapan Metode Economic Order Quantity Dalam Mewujudkan Efesiensi Biaya Persediaan". JIAK.Vol 1.No. 3.

Ikatan Akuntansi Indonesia. 2008. Standar Akuntansi Keuangan. Penerbit Salemba. Jakarta.

Indrayati. 2007. Analisis Pengendalian Persediaan Bahan Baku dengan Metode EOQ pada PT Tipota Furnishing Jepara [Skripsi]. Fakultas Ekonomi Universitas Negeri Semarang.

Martono, Herjanto. 2008. Manajemen Produksi dan Operasi. Penerbit Grasindo. Jakarta.

Mowen Hansen. 2005. Manajemen Akuntansi. Penerbit Salemba . Jakarta.

Pernyataan Standar Akuntansi Keuangan. No 14 (Revisi 2009) Persediaan. Dewan Standar Akuntansi Keuangan - Ikatan Akuntansi Indonesia . Jakarta.

Taslim, M. 2014. " Analisis Penerapan Metode Economic Order Quantity dan Reorder Point untuk Pengendalian Persediaan Bahan Baku”. FE Universitas Negeri Makassar. Vol 2 .No. 2.

Tuerah. 2014. “Analisis Pengendalian Persediaan Bahan Baku Ikan Tuna”. FEB Universitas Sam Ratulagi. Vol.2 No. 4 
Yamit. 2008. Manajemen Produksi dan Operasi, Penerbit PT Ekonisia, Yogyakarta. 